POLYMER SCIENCE AND TECHNOLOGY

Volume 10

\title{
POLYMER ALLOYS
}

Blends, Blocks, Grafts, and

Interpenetrating Networks 


\title{
POLYMER SCIENCE AND TECHNOLOGY
}

Editorial Board:

William J. Bailey

University of Maryland

College Park, Maryland

J. P. Berry

Rubber and Plastics Research Association

of Great Britain

Shawbury

Shrewsbury, England

\section{A. T. DiBenedetto}

The University of Connecticut

Storrs, Connecticut
C. A. J. Hoeve

Texas A\&M University

College Station, Texas

Yöichi Ishida

Osaka University

Toyonaka, Osaka, Japan

Frank E. Karasz

University of Massachusetts

Amherst, Massachusetts

Osias Solomon

Polytechnical Institute of Bucharest

Bucharest, Romania

\author{
Volume 1 - STRUCTURE AND PROPERTIES OF POLYMER FILMS \\ Edited by Robert W. Lenz and Richard S. Stein \\ Volume 2 - WATER-SOLUBLE POLYMERS \\ Edited by N. M. Bikales \\ Volume 3 - POLYMERS AND ECOLOGICAL PROBLEMS \\ Edited by James Guillet \\ Volume 4 - RECENT ADVANCES IN POLYMER BLENDS, GRAFTS, AND BLOCKS \\ Edited by L. H. Sperling \\ Volume 5 - ADVANCES IN POLYMER FRICTION AND WEAR (Parts A and B) \\ Edited by Lieng-Huang Lee \\ Volume 6 - PERMEABILITY OF PLASTIC FILMS AND COATINGS \\ TO GASES, VAPORS, AND LIQUIDS \\ Edited by Harold B. Hopfenberg \\ Volume 7 BIOMEDICAL APPLICATIONS OF POLYMERS \\ Edited by Harry P. Gregor \\ Volume 8 - POLYMERS IN MEDICINE AND SURGERY \\ Edited by Richard L. Kronenthal, Zale Oser, and E. Martin \\ Volume 9 - ADHESION SCIENCE AND TECHNOLOGY (Parts A and B) \\ Edited by Lieng-Huang Lee \\ Volume 10 - POLYMER ALLOYS: Blends, Blocks, Grafts, and Interpenetrating Networks \\ Edited by Daniel Klempner and Kurt C. Frisch
}

A Continuation Order Plan is available for this series. A continuation order will bring delivery of each new volume immediately upon publication. Volumes are billed only upon actual shipment. For further information please contact the publisher. 


\section{POLYMER ALLOYS}

Blends, Blocks, Grafts, and Interpenetrating Networks

Edited by

\section{Daniel Klempner} and Kurt C. Frisch 


\section{Library of Congress Cataloging in Publication Data}

Main entry under title:

Polymer alloys.

(Polymer science and technology; v. 10)

"Based on a symposium sponsored by the Division of Organic Coatings and Plastics Chemistry at the 173rd meeting of the American Chemical Society held in New Orleans, March 1977."

Includes index.

1. Polymers and polymerization - Congresses. I. Klempner, Daniel. II. Frisch, Kurt Charles, 1918- III. American Chemical Society. Division of Organic Coatings and Plastics Technology. IV. Series.

QD380.P636

668

$77-21559$

ISBN-13: 978-1-4684-0876-8

e-ISBN-13: 978-1-4684-0874-4

DOI: $10.1007 / 978-1-4684-0874-4$

Based on a symposium sponsored by the Division of Organic Coatings and Plastics Chemistry at the 173rd meeting of the American Chemical Society held in New Orleans, March, 1977

C 1977 Plenum Press, New York

Softcover reprint of the hardcover 1st edition 1977

A Division of Plenum Publishing Corporation

227 West 17th Street, New York, N.Y. 10011

All rights reserved

No part of this book may be reproduced, stored in a retrieval system, or transmitted, in any form or by any means, electronic, mechanical, photocopying, microfilming, recording, or otherwise, without written permission from the Publisher 
PREFACE

Alloy is a term commonly associated with metals and implies a composite which may be sinqle phase (solid solution) or heterophase. Whichever the case, metallic alloys generally exist because they exhibit improved properties over the base metal. There are numerous types of metallic alloys, including interstitial solid solutions, substitutional solid solutions, and multiphase combinations of these with intermetallic compounds, valency compounds, electron compounds, etc. A similar situation exists with polymers. There are numerous types of composites, or "alloys" of polymers in existence today with new ones being created continuously. Polyblends are simple physical mixtures of the constituent polymers with no covalent bonds occuring between them. As with metals, these may be homogeneous (single phase) solid solutions or heterogeneous (multiple phase) mixtures. With polymers, the latter case is by far the most prevalent situation due to the thermodynamic incompatibility of most polymers. This is due to the relatively small gain in entropy upon mixing the polymers due to contiguity restrictions imposed by their large chain length. If the component polymers in the blend are crosslinked, a relatively new situation arises. The resulting material is known as an interpenetrating polymer network(IPN). IPN's represent a mode of blending two or more crosslinked polymers to produce a mixture in which phase separation is not as extensive as would be otherwise, due to "permanent" entanglements occurina between the networks. If covalent bonds exist between the component polymers, a graft copolymer results. The term graft is employed since these copolymers (and they are true copolymers since the polymers are covalently bonded to each other) are generally produced by "grafting" a growing chain of one polymer onto a chain of another polymer. If the differing monomer units are arranged linearly in segments covalently bonded 
to one another along the chain, a block copolymer results. Phase separation generally occurs with the latter types of polvmer composites, although it is not as extensive as in the case of polyblends.

As with metals these "polymer alloys" generally exhibit enhanced and in many cases synergistic properties. Indeed, this is the major impetus for their formation. Determination of the morphology of these composites has presented a unique challenge to polymer scientists and engineers. This book presents a compilation of the most recent efforts of both American and foreign scientists in one of the most active areas of polymer research today, the study of the preparation, characterization, and properties of polymer alloys. The major portion of the chapters in this book was presented at a symposium sponsored by the Division of organic Coatings and Plastics Chemistry at the 173rd meeting of the American Chemical Society, held in New Orleans in March, 1977.

The editors wish to express their gratitude to the numerous authors who contributed to this book and to the University of Detroit for its encouragement of this effort.

Daniel Klempner

Polymer Institute

Kurt C. Frisch

University of Detroit 
Contents

Advanced Polymer Alloys Containina Poly-

Phosphonate Components . . . . . . . . . .

I. Cabasso, J. Jagur-Grodzinski, and D. Vofsi

An Approach to New Polymeric Materials via

Blocks, Grafts, and Blends . - . . . . . . .

James R. Kenney

The Crystallization Behavior of Blends of Low Density Polyethylene and $\operatorname{Poly}(\varepsilon$-Caprolactone) . . . . . .

D. Krevor and P. J. Phillips

Elastomer Blends - Improved Strength Properties of Uncured Rubber Compounds - . - . . . . . .

Emil M. Friedman, Richard G. Bauer, and Diego C. Rubio

Physical and Mechanical Properties and Morphology of Mixtures of High Impact Polystyrene with Homopolystyrene . . . . . . . . . . . . . . . .

B. V. Kravchenko and V. D. Yenalyev

Rheoptical studies of Blends of Poly (Styrene-BButadiene-B-Styrene) and Polystyrene . . . . . .

S. D. Hong, M. Shen, T. Russell and R. S. Stein

Barrier and Surface Properties of Poly-

urethane-epoxy Interpenetrating Polymer Networks - .

H. L. Frisch, J. Cifaratti, R. Palma, R. Schwartz,

R. Foreman, H. Yoon, D. Klémpner, and K. C. Frisch

Novel Plastics and Elastomers from Castor Oil Based IPN's: A Review of an International Program . . .

L. H. Sperling, J. A. Manson, G. M. Yenwo,

N. Devia-Manjarres, J. Pulido, and A. Conde 
Normal and Unusual Morphologies in Blends of $A B-$

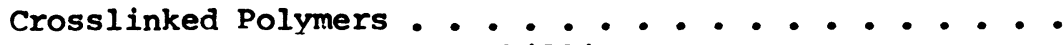

G. C. Eastmond and D. G. Phillips

Block-Graft Copolymers by Grafting Pivalolactone to

Polyisoprene and Polyisobutylene . . - . . . . . .

W. H. Sharkey, R. P. Foss, and J. F. Harris, Jr.

Graft Copolvmers of Pivalolactone: Synthesis and

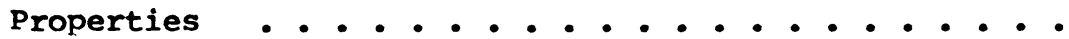

S. A. Sundet and R. C. Thamm

Physical Characterization of Pivalolactone Grafted

Elastomers II. Orientation Behavior . - . . . . . .

W. H. Buck

Syntheses of Block Copolymers by Ring-Opening

Polymerization

Yuya Yamashita

The Preparation of Styrene Block Copolymers from Macroradicals Produced in Viscous Media . . . . . . . G. Allan Stahl and Raymond B. Seymour

Phase Separation in Styrene- $\alpha$-Methyl Styrene

Block Copolymers - . . . . . . . . . . . . . .

Sonja Krause and Magdy Iskandar

The Dependence of the Dynamic Mechanical Properties of Poly [(1,4-Cyclohexane) Bismethylene Isophthalate]b-Polycaprolactone Copolymers on Segment size and Crystallinity . . . . - . . - . - . . . . . . . J. E. Herweh, J. L. Work, and W. Y. Whitmore

Structure-Property Relationships of Polyurethanes

Based on Toluene Diisocyanate . - . . . . . . . .

C. S. Paik Sung and N. S. Schneider

Effect of Annealing on the Morphology and Properties of Thermoplastic Polyurethanes . . . . . . . . C. H. M. Jacques

The Effect of Cross-linking on the Dynamic Mechanical Properties of an Incompatible, Segmented Polyurethane. . 
Interaction of Water with Hydrophilic Polyether Polyurethanes: DSC Studies of the Effects of

Polyether Variations . . . . . . . . . . . .

Joyce L. Illinger

Some Recent Developments in Rubber Modified Polymers. Influence of Block and Graft Copolymers on Morphology and Properties . . . . . . .

G. Riess, S. Marti, J. L. Refregier and M. Schlienger

Grafting Kinetics in the Case of Rubber Modified

Polymers. ABS and HIPS Systems ...........

G. Riess, C. Beslin, J. L. Locatelli and J. L. Refregier

Thermal Graft Copolymerization of Styrene with Rubber

I. Kinetics of Graft Copolymerization of Styrene

with Polybutadiene ..................

V. D. Yenalyev, N. A. Noskova, V. I. Melnichenko,

O. P. Bovkunenko, and O. M. Mezentseva

Thermal Graft Copolymerization of Styrene with Rubber. II. Topochemistry of Styrene Copolymerization with Polybutadiene in Bulk and its Connection with High Impact Polystyrene Morphology ........... . . . . . . . . V. D. Yenalyev, N. A. Noskova, and V. I. Melnichenko

Thermal Graft Copolymerization of Styrene with Rubber III. Temperature Regime Influence of Styrene Copolymerization with Polybutadiene on High Impact Polystyrene

Morphology .....................

V. D. Yenalyev, N. A. Noskova, and S. Hohne

Thermal Graft Copolymerization of Styrene with Rubber IV. The Peculiarities of the Process of Producing High Impact Polystyrene by Means of Continuous Methods . . . . . . V. D. Yenalyev, N. A. Noskova, B. V. Kravchenko, and V. A. Gasin

Grafting Isobutylene From SBR ... . . . . . .

James Oziomek and Joseph P. Kennedy

Synthesis and Characterization of Poly(Chloroprene-g-

Isobutylene) . . . . . . . . . . . . . .

D. K. Metzler and J. P. Kennedy 
Kinetics and Mechanism of the Early Stages of Polymerization in the Styrene-Polybutadiene System ..... W. A. Ludwico and S. L. Rosen

Graft Copolymerization of Vinyl Monomers with Synthetic Rubbers in the Presence of Complexing Agents ...... R. V. Kucher, Ju. S. Zaitsev, A. A. Kuznetsov, and

V. V. Zaitseva

Viscoelastic Properties of Poly(ethylene-G-styrene). . .

J. Diamant, D. R. Hansen and M. Shen

Synthesis and Thermal Analytical Characterization of Chlorinated Poly-ethylene-g-styrene ... . . . . Carl E. Locke and Larry Watters

Photoassisted Modification of and Grafting to Polyethylene

James F. Kinstle and Stuart L. Watson, Jr.

List of Contributors ...............

Index .......................... 